IFN Working Paper No. 682, 2006

\title{
Industry Concentration and Welfare - On the Use of Stock Market Evidence from Horizontal Mergers
}

Sven-Olof Fridolfsson and Johan Stennek 


\title{
Industry Concentration and Welfare -
}

\author{
On the Use of Stock Market Evidence from Horizontal Mergers*
}

Sven-Olof Fridolfsson

RIIE

\author{
Johan Stennek
}

RIIE and CEPR

November 22, 2006

\begin{abstract}
There is diverging empirical evidence on the competitive effects of horizontal mergers: consumer prices (and thus presumably competitors' profits) often rise while competitors' share prices fall. Our model of endogenous mergers provides a possible reconciliation. It is demonstrated that anticompetitive mergers may reduce competitors' share prices, if the merger announcement informs the market that the competitors' lost a race to buy the target. Also the use of "first rumor" as an event may create similar problems of interpretation. We also indicate how the event-study methodology may be adapted to identify competitive effects and thus, the welfare consequences for consumers.
\end{abstract}

Key Words: mergers \& acquisitions; event studies; antitrust; in-play; coalition formation.

JEL classification: L41; L12; G14; G34.

\footnotetext{
${ }^{*}$ We are grateful to Hans Carlsson, Raymond Deneckere, Stephen Martin and Patrick Rey for valuable comments, as well as to participants at seminars at FIEF, IDEI, RIIE, Stockholm University, UC Berkeley, SAET on Rhodos, IIOC in Chicago and EEA in Wienna. Fridolfsson thanks IDEI and University of Toulouse for providing a stimulating research environment while working on this paper. He also thanks the Swedish Competition Authorithy and Jan Wallander's and Tom Hedelius' Research Foundation for financial support. Stennek thanks Jan Wallander's and Tom Hedelius' Research Foundation for financial support. Address: Research Institute of Industrial Economics (RIIE), P.O. Box 55665, SE-10215 Stockholm, Sweden.
} 


\section{Introduction}

High market concentration allows firms to exploit economies of scale, but also to wield market power. While profits are often assumed to increase with concentration, it is generally acknowledged that customers are better or worse off, depending on the relative importance of market power and scale economies; the effect on customers must be empirically assessed. Many empirical studies use horizontal mergers as natural experiments, since such events give rise to observable and significant changes in market concentration during a relatively short period of time. ${ }^{1}$

By now, the empirical literature contains numerous tests of whether mergers are mainly motivated by market power or efficiency gains, but differences in methodology have created diverging results. Studies of consumer pricing indicate that consolidations lead to less competition, see for example Barton and Sherman (1984) on microfilm, Borenstein (1990), Werden et al (1991) and Kim and Singal (1993) on the airline industry, Prager and Hannan (1998) on the banking industry and Dafny (2005) for an analysis of hospital mergers. More recently, however, Focarelli and Panetta (2003) have argued that possible anticompetitive effects are immediate, but that synergies typically take some time to achieve, and that it is therefore essential to investigate the longrun price effects of mergers. Consistent with the previous literature, they find strong adverse effects on prices, but only in the short run. In the long run, efficiency gains dominate in their sample, collected from the bank deposit

\footnotetext{
${ }^{1}$ The interest in horizontal mergers and their effect on consumer welfare is also motivated by policy considerations. Merger control is one of the few political instruments for directly affecting market concentration inside a country and, in most countries, the goal of merger control is to protect consumer welfare. The techniques developed and the results obtained in this area of research may, thus, have the potential additional benefit of guiding policy makers in designing and evaluating their control system, as well as guiding individual decisions (see eg Eckbo, 1983, and Neven and Röller, 2002).
} 
market. Although the time aspect is an important potential qualifier, by and large, these studies indicate that increased market power dominates possible efficiency gains, at least from a consumer perspective. Complementary evidence, comparing different geographical markets, also suggests a positive relation between concentration and consumer prices.

Another strand of the literature studies the effect of mergers on competing firms' share prices. If efficiency gains are small as compared to the increase in market power, consumer prices will increase and thus competitors will benefit while consumers lose. With strong synergies, consumers will benefit and competitors lose. Relying on this inverse relationship between competitors' profits and consumer welfare, and the assumption that share prices reflect firms' profits, it may be inferred how a merger affects consumers, by observing the change in the competitors' stock market values. Some studies show that competitors do not benefit from horizontal mergers (Eckbo, 1983; Stillman, 1983; Schumann, 1993) and others that competitors suffer significant value losses (Bradley, Desai and Kim, 1983; Banerjee and Eckard, 1998). In Neven and Röller (2002) the results are mixed. By and large, the evidence from event studies of rivals' returns is thus consistent with the efficiency hypothesis.

There are many possible reasons why the two methods suggest diverging conclusions about the welfare effects of market concentration. An advantage of consumer price studies is that they measure the relevant variable directly; a disadvantage is that they must be extended over a long period of time to capture the synergy effects. Many other factors may also change during such a period, thereby making it difficult to isolate the effect of the merger.

The apparent inconsistency may also be due to different studies including different mergers in their samples. This explanation is unlikely, however, 
since each method has been used repeatedly and has been found to yield relatively consistent results. Moreover, McAfee and Williams (1988) study a merger with known competitive effects. Even though this particular merger increased consumer prices, the competitors' share prices were (insignificantly) reduced, and the authors conclude that event studies may fail to identify the competitive effects of mergers. The present paper attempts to further investigate this issue, without intending to play down the problems associated with price studies.

One possible problem with event studies of rivals' returns is that the presumed inverse relation between consumer welfare and competitors' profits may be weak. McAfee and Williams report that the rivals in their sample were large multi-product firms, only deriving a small fraction of their revenues from the affected market. Neven and Röller (2002) argue that if the efficiency gains are sufficiently strong, the competitors may prefer to leave the market, in which case both competitors and consumers are hurt. We will simply presume that the inverse relationship exists, and scrutinize the second link - the idea that changes in share prices reflect changes in profits.

The standard interpretation of event studies builds on the so-called semistrong form of the efficient market hypothesis, which posits that the market price of common stock reflects all publicly available information, combined with the hypothesis that the merger announcement comes as a surprise to the market. As a result, pre-merger share prices do not reflect merger opportunities; they only reflect the firms' profits prior to the merger. If post-merger share prices also reflect post-merger profits, the change in share prices reflects the change in the profit level. A possible reason why a merger announcement may come as a surprise to the market is that, before the announcement, the merger is private information, so that the pre-merger share-prices are based 
on the erroneous presumption that the current market structure will persist indefinitely.

Even a casual reading of the business press undermines the confidence in the generality of this line of reasoning, however. Since mergers are typically rational adaptations to identifiable changes in industry-wide market conditions, ${ }^{2}$ they are often anticipated. ${ }^{3}$ As these anticipations often reach the press, they are highly likely to also affect share-prices. Typically, there is some remaining uncertainty about if and when a merger will occur and therefore, the merger announcement carries information. The literature on conditional event studies shows how to extract this information, explicitly dealing with anticipations (Acharya, 1988 and 1993; Eckbo, Maksimovic and Williams, 1990; Prabhala, 1997). Essentially, when mergers are anticipated, changes in stock market values under-estimate changes in profits. Such a bias towards zero may not be a crucial problem in the present context, however, since we are primarily interested in the sign.

A potentially more severe problem is that there is often uncertainty about the exact identity of the acquirer and the target. There may be several candidates for both roles. For example, Financial Times (February 24, 2004, p. 36) reported on takeover activities in the European banking sector and listed three German firms as potential takeover candidates. A few days earlier, Financial Times (February 17, 2004, p. 31) reported on the battle between Vodafone and Cingular to take over AT\&T Wireless. This uncertainty about the allocation of roles (buyer, seller and outsider) may complicate how the

\footnotetext{
${ }^{2}$ See Mitchell and Mulherin (1996) and Jovanovic and Rousseau (2001).

${ }^{3}$ Bradley, Desai and Kim (1983) find evidence that pre-merger share prices incorporate expectations of mergers and similar evidence by Fabozzi, Ferri, Fabozzi and Tucker (1988) also suggests that stock markets do not anticipate unsuccessful bids. Song and Walkling (2000) find evidence for so-called in play effects: mergers may themselves raise anticipations of future mergers.
} 
merger anticipations are incorporated in the share prices.

Thus, in our view, event studies of rivals' returns are built on informal and overly simplified ideas about the relationship between share prices and the welfare effects of mergers. To deal with these issues, we provide a formal bridge between the two. The model is introduced in Section 2 and has three ingredients. First, we use standard oligopoly theory to describe the interaction between firms and consumers in the product market. The oligopoly model shows how mergers affect both the profits of the merging firms and their competitors as well as the welfare of their customers; it also shows how changing market conditions - triggers - influence merger incentives. Second, we use endogenous merger theory to analyze firms' incentives to form coalitions in a market. In particular, we use an extensive form model of coalitional bargaining to describe the acquisition process. Firms take turns submitting merger proposals to their competitors, which can either accept or reject them. In the latter case, new proposals can be made in the future. As a consequence, firms endogenously decide whether and when to merge, and how to split the surplus while keeping alternative mergers in mind. Third, we let the firms' share prices be determined in a stock market equilibrium. In the spirit of the efficient market hypothesis, we assume share prices to reflect expected discounted profits, and the stock market to understand firms' incentives both in the product market and the acquisition game.

In Section 3, we show that event studies of rivals' returns may not have been appropriately interpreted. If mergers reduce competition but increase cost efficiency, participants' profits may increase more than rivals' profits, inducing a race for targets; with efficient stock markets, rivals' share prices may fall when a merger is announced, as they lost the race. We call this the out-of-play effect. It immediately follows that a reduction in rivals' values 
does not imply that a merger is pro-competitive. ${ }^{4}$ This result provides a possible reconciliation of the diverging empirical evidence on the welfare effects of horizontal mergers.

A second issue concerns the fact that mergers are triggered by changes in market conditions, such as deregulation, factor price changes, foreign competition and technological innovations. The shocks affect prices, profits and share prices, thus making it difficult to identify the effect of the merger. It is often said that a main advantage with event studies is that share prices are forward-looking and thus, that the effect of a merger may be assessed using a short window of observation (see eg MacKinlay, 1997). However, we show that a short window may be counterproductive.

We also discuss alternative procedures for identifying the welfare effects of horizontal mergers using stock market data. Actually, Banerjee and Eckard (1998) were aware of anticipation effects, and attempted to eliminate them by defining the first rumor of merger as the event. While this method does not necessarily identify the competitive effect, we also show that combining evidence from the first rumor with the evidence from the merger announcement may be a better empirical strategy. Hereby, we provide an equilibrium justification for the event study methodology, albeit with a somewhat different procedure.

\section{The Model}

Consider an industry with three identical firms, each earning a continuoustime profit flow, denoted $\pi_{s}$, where $s$ indicates the state of the market, eg the

\footnotetext{
${ }^{4}$ Eckbo (1983) argues that a merger announcement may signal that outsiders are potential targets in future mergers bringing similar gains. As a result of this in-play effect, a pro-competitive merger which reduces outsiders' profits may increase their share prices.
} 
level of demand or the cost of production. If they so wish, any two firms may merge and turn the market into a duopoly. The merged and the outsider firms earn profit flows $\pi_{s}^{+}$and $\pi_{s}^{-}$, respectively. Mergers to monopoly are illegal, however. In line with the event study literature, the competitive nature of a merger is assumed to be related to the externality on the competing firm. Hence, a merger is anti-competitive if $\pi_{s}^{-}>\pi_{s}$ and pro-competitive otherwise. These profit flows are derived in an explicit oligopoly model below.

Mergers are often triggered by identifiable changes in industry-wide market conditions, such as deregulation, factor price changes, foreign competition and technological innovations (Mitchell and Mulherin, 1996; Jovanovic and Rousseau, 2001). To model the trigger in a simple way, we assume that the market is hit by an industry-wide shock, exemplified by an increase in demand, moving the industry from state $y$ to state $z$. Prior to the shock, it is unprofitable to merge, ie $\pi_{y}^{+}<2 \pi_{y}$; afterwards it is profitable, ie $\pi_{z}^{+}>2 \pi_{z}$. The shock occurs at a random point in time, but is anticipated by all agents. The probability of a shock having occurred by time $t$ is described by the cumulative distribution function $F(t)=1-e^{-\lambda t}$, with the constant hazard rate $f(t) /(1-F(t))=\lambda \in(0, \infty)$, where $f(t)$ is the probability density function. ${ }^{5}$

The Acquisition Game In the spirit of Rubinstein-Ståhl bargaining, the acquisition process is modeled as a multi-stage (three-person) bargaining

\footnotetext{
${ }^{5}$ The theoretical literature on mergers has mainly left the issue of triggers unanalyzed. Except for Dutz (1989), the exogenous merger literature (see eg Salant, Switzer and Reynolds, 1983, Deneckere and Davidson, 1985, Perry and Porter, 1985, and Farrell and Shapiro, 1990) focuses on the effects of mergers, assuming the market conditions to be fixed. Similarly, except for Gowrisankaran (1998), the endogenous merger literature (see eg Kamien and Zang, 1990 and 1993, and Horn and Persson, 2001a-b) analyzes which firms will merge when several alternatives are possible, assuming the market conditions to be fixed.
} 
game with an infinite horizon. The bidding rounds occur at random points in time. In each round, a randomly selected firm is given the opportunity to submit a bid for some other firm, and the target can either accept or reject the bid. The proposal and the reply are assumed to take no time. Once a merger from triopoly to duopoly occurs, the bargaining ends. At any time $t$, the probability of the next bidding round having occurred by time $t+\Delta$, is described by the cumulative distribution function $G(\Delta)=1-e^{-\mu \Delta}$, with the constant hazard rate $g(\Delta) /(1-G(\Delta))=\mu \in(0, \infty)$, where $g(\Delta)$ is the probability density function. Thus, at any time, the expected time until the next bidding round is given by $\int_{0}^{\infty} \Delta g(\Delta) d \Delta=1 / \mu$. $\mu$ is interpreted as a measure of the speed of decision-making in the firms.

A strategy describes a firm's behavior in the multi-stage bargaining game: whether and how much to bid, and a reservation price at which to accept offers. We restrict the attention to symmetric Markov perfect equilibria, which implies that strategies only depend on the current state. Such an equilibrium is characterized by $\left(p_{s}, b_{s}, a_{s}\right)$ for both states $s \in\{y, z\}$, where $p_{s} \in[0,1 / 2]$ denotes the probability of a firm bidding for one specific firm in any bidding round in state $s, b_{s}$ denotes the size of this bid, and $a_{s}$ the lowest bid a target firm will accept.

The firms know their stock market values in both market structures and both states. Let $W_{s}$ denote the value of a triopoly firm in state $s$, and $W_{s}^{+}$ and $W_{s}^{-}$denote the values of the merged firm and the outsider, respectively. These values are computed below. The equilibrium in the acquisition game is described by three conditions for each state. First, by subgame perfection, an offer is accepted iff the bid is at least as high as the value of the firm. Second, a bidder does not offer more. Hence, $b_{s}=a_{s}=W_{s}$. Third, a firm bids iff bidding maximizes its value. If the firm does not bid, its value is $W_{s}$. 
If it bids, the value is $W_{s}^{+}-b_{s}$. Hence, in equilibrium,

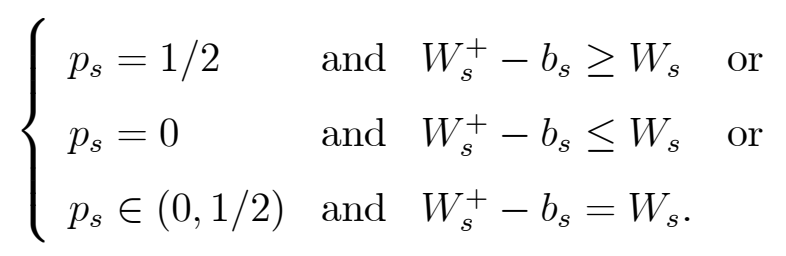

Note that a merger does not occur in state $s$ if $p_{s}=0$. We say that there is a merger race if $p_{s}=1 / 2$ and a merger hold-up equilibrium if $p_{s} \in(0,1 / 2)$.

The Stock Market To model the stock market equilibrium, we assume the stock market to be efficient. In particular, the stock market value of a firm equals the expected discounted sum of future profits (which are continuously distributed as dividends). Moreover, the stock market anticipates the shock and can predict the equilibrium both in the oligopoly game and the acquisition game.

If a merger occurs in state $z$, the equilibrium stock market values of the merged firm $(+)$ and the outsider firm (-) are given by

$$
W_{z}^{i}=\int_{0}^{\infty} \pi_{z}^{i} e^{-r \tau} d \tau=\pi_{z}^{i} / r
$$

for $i \in\{+,-\}$, where $r$ is the interest rate. If a merger to duopoly occurs in state $y$, the equilibrium stock market values of the firms in the duopoly are given by

$$
\begin{aligned}
W_{y}^{i} & =\int_{0}^{\infty}\left(\int_{0}^{t} \pi_{y}\left(2^{i}\right) e^{-r \tau} d \tau+\int_{t}^{\infty} \pi_{z}\left(2^{i}\right) e^{-r \tau} d \tau\right) f(t) d t \\
& =\frac{r}{r+\lambda} \pi_{y}^{i} / r+\frac{\lambda}{r+\lambda} \pi_{z}^{i} / r
\end{aligned}
$$

for $i \in\{+,-\}$, which is a weighted average of the profit flows before and 
after the shock.

To simplify the definition of the stock market value of a triopoly firm in state $s$, we first define the firm's value at the time of a bidding round, before the identity of the bidder is revealed, as

$$
V_{s}=\frac{2}{3} p_{s}\left(W_{s}^{+}-b_{s}\right)+\frac{2}{3} p_{s} b_{s}+\frac{2}{3} p_{s} W_{s}^{-}+\left(1-2 p_{s}\right) W_{s}
$$

The values of becoming a buyer $\left(W_{s}^{+}-b_{s}\right)$, seller $\left(b_{s}\right)$, outsider $\left(W_{s}^{-}\right)$and remaining triopolist $\left(W_{s}\right)$ are simply multiplied by the corresponding probabilities. For example, the probability of becoming a buyer is $\left(2 p_{s}\right) / 3$, since a firm is selected to bid with probability $1 / 3$, and it bids for each of the other two firms with probability $p_{s}$. The stock market value of a triopoly firm in state $z$ is then given by

$$
\begin{aligned}
W_{z} & =\int_{0}^{\infty}\left[\left(1-e^{-r \Delta}\right) \pi_{z} / r+e^{-r \Delta} V_{z}\right] g(\Delta) d \Delta \\
& =\frac{r}{r+\mu} \pi_{z} / r+\frac{\mu}{r+\mu} V_{z} .
\end{aligned}
$$

The first term corresponds to the discounted profits until the next bidding round, and $V_{z}$ is the value of the firm at a bidding round before the bidder's identity is revealed. Since the length of time until the next bidding, ie $\Delta$, is random, the expected value of a triopoly firm is obtained by integrating over $\Delta$. Similarly, the stock market value of a triopoly firm in state $y$ is given by

$$
\begin{gathered}
W_{y}=\int_{0}^{\infty}\left\{F(\Delta)\left[\int_{0}^{\Delta}\left(\int_{0}^{t} \pi_{y} e^{-r \tau} d \tau+\int_{t}^{\Delta} \pi_{z} e^{-r \tau} d \tau\right) \frac{f(t)}{F(\Delta)} d t+e^{-r \Delta} V_{z}\right]\right. \\
\left.+(1-F(\Delta))\left[\int_{0}^{\Delta} \pi_{y} e^{-r \tau} d \tau+e^{-r \Delta} V_{y}\right]\right\} g(\Delta) d \Delta \\
=\frac{\lambda}{\lambda+r+\mu}\left(\frac{r}{r+\mu} \pi_{z} / r+\frac{\mu}{r+\mu} V_{z}\right)+\frac{r+\mu}{\lambda+r+\mu}\left(\frac{r}{r+\mu} \pi_{y} / r+\frac{\mu}{r+\mu} V_{y}\right)
\end{gathered}
$$


where $F(\Delta)$ is the probability of a shock having occurred before the next bidding round. $W_{y}$ is a weighted average of profit flows before and after the shock, taking into account that there may be a merger in any state.

\subsection{Equilibrium}

Our main focus is to delineate the conditions under which there exists an equilibrium where (i) firms do not merge prior to the shock, ${ }^{6}$ and (ii) there is a merger race subsequent to the shock. Working backwards, our analysis starts with the equilibrium in case the triopoly remains after the shock.

Equilibrium Subsequent to Shock Lemma 1 (in Appendix A) describes the equilibrium in case the triopoly remains after the shock has occurred. Firms do have an incentive to merge in state $z$, since mergers are assumed to be profitable, ie $\pi_{z}^{+} / 2>\pi_{z}$. But there is also an additional motive for merger. If it is better to be an insider than an outsider, ie $\pi_{z}^{+} / 2>\pi_{z}^{-}$, firms bid for their rivals also to avoid becoming an outsider themselves. This preemption motive is especially strong when firms expect their rivals to bid soon ( $\mu$ is high). In fact, if

$$
\frac{r}{r+\mu}\left(\pi_{z}^{+} / 2-\pi_{z}\right)+\frac{\mu}{r+\mu}\left(\pi_{z}^{+} / 2-\pi_{z}^{-}\right) / 3 \geq 0
$$

there is a merger race, and a merger occurs as soon as possible. ${ }^{7}$

\footnotetext{
${ }^{6}$ In fact, the whole point of including a state prior to the shock in the model is to ensure that the market will be in a non-merged state (triopoly) for a non-negligible period of time.

If instead it is significantly better to be an outsider, reversing inequality (7), firms delay their merger proposals and thereby forego valuable profits, since they hope other firms will merge instead - much like a war of attrition.
} 
Equilibrium Prior to Shock Prior to the shock, the decision problem facing the firms is related to the problem of optimal investment timing and real options (see Dixit, 1992). In state $y$, there is a value in waiting to acquire another firm. Since a merger is profitable in state $z$ but unprofitable in $y$, the optimal time of merger is at the time of the shock. Due to the lack of merger partners, however, there may be competition to participate in a merger, and waiting may entail the risk of becoming an outsider.

Lemma 2 (in Appendix A) describes the equilibrium prior to the shock. Since $\pi_{y}^{+}<2 \pi_{y}$, the only reason to merge already before the shock would be to reduce the risk of becoming an outsider in a merger following the shock. ${ }^{8}$ In fact, if inequality (7) is fulfilled, and there is a merger race after the shock, the firms' incentives prior to the shock are determined by the expected waiting time until the shock will occur, ie by $\lambda$. When the likelihood of a shock is sufficiently small, that is if

$$
\lambda \leq \lambda_{\text {NoMerger }},
$$

where $\lambda_{\text {NoMerger }}$ is defined in the Lemma, there exists a no-merger equilibrium. In this case, firms put a large weight on the immediate cost of merging (the merger reduces profits prior to the shock) and a small weight on the future gain (the value of becoming an insider rather than an outsider).$^{9}$

\footnotetext{
${ }^{8}$ In the lemma, we also assume that $\pi_{y}^{+} / 2<\pi_{y}^{-}$to eliminate equilibria where firms merge for the sole reason that it is better to become an insider than an outsider in $y$. For an extensive discussion of such preemptive motives, see Fridolfsson and Stennek (2000).

${ }^{9}$ Lemma 2 also demonstrates that when the likelihood of the shock is sufficiently large, $\lambda \geq \lambda_{\text {Race }}$, there exists a merger race equilibrium. In this case, firms put a large weight on the future benefit and a small weight on the immediate cost of merging (taking into account that the relevant alternative to the merger is to become an outsider already before the shock). For intermediate values of the hazard rate, there is a merger hold-up equilibrium. Note that if $\lambda_{\text {NoMerger }}<\lambda_{\text {Race }}$, there exists a unique symmetric Markov perfect equilibrium for all $\lambda$. Otherwise, all three types of equilibria exist for the intermediate values of $\lambda$. Finally, Lemma 2 demonstrates that if inequality (7) is reversed, ie if it is
} 


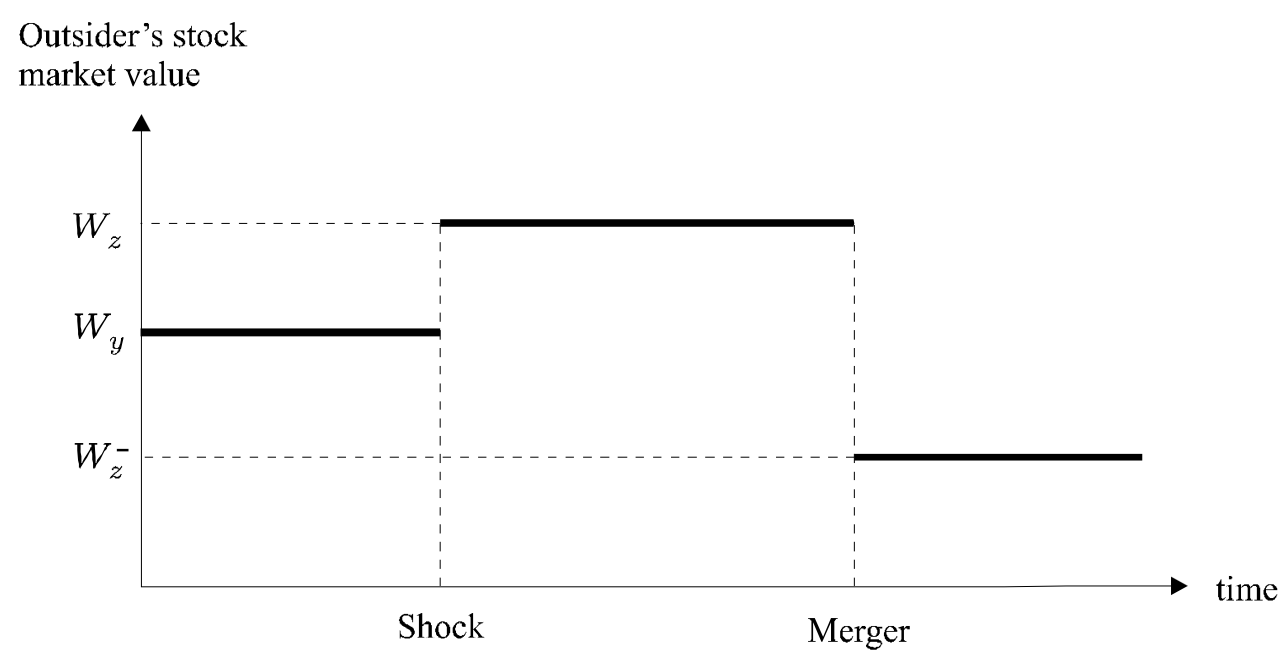

Figure 1: The evolution of the outsider's stock market value.

\section{Why Rivals' Returns Fail to Identify Com- petitive Effects}

When there is a merger race subsequent to the shock (inequality 7 ), but firms do not bid prior to the shock (inequality 8), the outsider's stock market value is given by $W_{y}$ prior to the shock, $W_{z}$ in the intermediate period between the shock and the merger, and $W_{z}^{-}$subsequent to the merger. A possible evolution of the stock market value is depicted in Figure 1. The exact values, computed in Lemmas 1 and 2, are given by

$$
\begin{aligned}
& W_{y}=\frac{r}{\lambda+r} \pi_{y} / r+\frac{\lambda}{\lambda+r}\left(\frac{r}{r+\mu} \pi_{z} / r+\frac{\mu}{r+\mu}\left(\pi_{z}^{+}+\pi_{z}^{-}\right) / 3 r\right), \\
& W_{z}=\frac{r}{r+\mu} \pi_{z} / r+\frac{\mu}{r+\mu}\left(\pi_{z}^{+}+\pi_{z}^{-}\right) / 3 r \\
& W_{z}^{-}=\pi_{z}^{-} / r
\end{aligned}
$$

better to be an outsider subsequent to the shock, firms will not bid prior to the shock. 
Note that $W_{z}$ gives some weight to the pre-merger profit level, $\pi_{z}$. Since a merger is anticipated and each firm becomes an acquirer, target or outsider with equal probability, $W_{z}$ also gives some weight to the average post-merger profit level in the market, $\left(\pi_{z}^{+}+\pi_{z}^{-}\right) / 3$. The weight on the post-merger profit level is determined by the speed of the merger process, $\mu$. Furthermore, note that $W_{y}$ gives some weight to the profit level prior to the shock, $\pi_{y}$, but also to the profit level subsequent to the shock, taking into account merger anticipations.

We denote the change in the outsider's stock-market value at the time of the merger announcement by $\Delta W^{\text {merger }}=W_{z}^{-}-W_{z} \cdot{ }^{10}$ The central question is how $\Delta W^{\text {merger }}$ relates to the change in the discounted sum of the outsider's profits caused by the merger, ie $\left(\pi_{z}^{-}-\pi_{z}\right) / r$. The profit effect is positive if the merger is anti-competitive, and negative otherwise.

Proposition 1 Assume there to be a merger race subsequent to the shock (inequality 7), but that firms do not bid prior to the shock (inequality 8). Then,

$$
\Delta W^{\text {merger }}=\frac{r}{r+\mu} \underbrace{\left(\pi_{z}^{-}-\pi_{z}\right) / r}_{\text {profit effect }}-\frac{\mu}{r+\mu} \underbrace{\frac{2}{3}\left(\pi_{z}^{+} / 2-\pi_{z}^{-}\right) / r}_{\text {out-of-play effect }} .
$$

All proofs are relegated to Appendix A.

The proposition provides a conditional equilibrium foundation for the use of rivals' returns to identify the competitive effects of mergers.

Corollary 1 (a) The change in the outsider's stock-market value, at the time of the merger announcement, identifies the profit effect, ie $\Delta W^{\text {merger }}=$ $\left(\pi_{z}^{-}-\pi_{z}\right) / r$, if firms react very slowly to changing market conditions, ie $\mu \rightarrow 0$.

\footnotetext{
${ }^{10}$ Due to the simplicity of our model, the merger and the merger announcement occur at the same time, and we assume the length of the event window to be negligible.
} 
Intuitively, the share prices before the merger (but after the shock) assign a large weight to the pre-merger profit flow in state $z$, ie $W_{z} \approx \pi_{z} / r$, since a merger is expected in the far future. Since the post-merger share-prices are determined by the post-merger profit flow, the change in share-prices reflects the profit effect. Note that this result also conforms with the common interpretation of event studies, since the merger announcement comes as a complete surprise (in the sense of information theory) to the market. ${ }^{11} 12$

In general, there are two sources of mis-specification. The first misspecification is that even if share-price movements include a profit effect, ie $\left(\pi_{z}^{-}-\pi_{z}\right) / r$, this effect is discounted by $\frac{r}{r+\mu}<1$. Since the merger is partially anticipated, a fraction of the change in profit is incorporated into the share price already prior to the merger, and the change in the market value is biased towards zero. As this bias has been discussed in the literature on conditional event-study methods (Acharya, 1988 and 1993; Eckbo, Maksimovic and Williams, 1990; Prabhala, 1997), we do not dwell on it here.

The second mis-specification is the out-of-play effect. When it is better to be an insider than an outsider, firms compete to participate in the merger. With rational expectations, the pre-merger value of the outsider is high, since it reflects the possibility of becoming an insider. Once the merger has been announced, this possibility is eliminated, and the outsider's share price tends

\footnotetext{
${ }^{11}$ In fact, it can be shown that the correct measure of the surprise evoked by the occurrence of an event having probability $q$ is given by $S(q)=-\ln q$. (The result follows from two axioms, namely that (i) $S$ is decreasing in $q$ and that (ii) $S$ is additive over independent events.) Since the probability that a merger will be announced within $\tau$ time units is $\int_{0}^{\tau} g(\Delta) d \Delta=1-e^{-\mu \tau}$, the merger announcement comes as a complete surprise if firms react very slowly to the shock, ie $\lim _{\mu \rightarrow 0} S\left(1-e^{-\mu \tau}\right)=\infty$.

${ }^{12}$ That the merger announcement comes as a complete surprise does not guarantee that an event study identifies the profit effect, however. A merger comes as a surprise to the market also if firms respond very quickly to the shock ( $\mu$ is very high), but the shock itself is unexpected ( $\lambda$ is very low). In this case, however, rivals' returns will not identify the profit effect.
} 
to be reduced. Expressed differently, the merger announcement informs the stock market that the outsider lost the race to participate in the merger, and that the outside firm is now out of play.

While Proposition 1 identifies the determinants of the evolution of the outsider's stock market value, it does not state which is the dominating effect. However, by way of example, it is easily proved that the outsider's profit and stock market value may move in opposite directions.

Corollary 1 (b) An anti-competitive merger may reduce the stock market value of a competitor.

The Corollary provides a possible reconciliation of the diverging empirical evidence on the welfare effects of horizontal mergers.

To construct a simple example, we consider a linear homogenous good Cournot triopoly, with a fixed amount of capital in the market (see the proof of the Corollary). A merger gives the insider an opportunity to reduce the marginal cost, eg by integrating their plants, transferring knowledge or specializing production. To realize these synergies, the firm must invest in restructuring, however. Depending on the size of the marginal cost reduction, the merger is anti- or pro-competitive. To conform with the stylized fact that aggregate merger activity is pro-cyclical (Weston, Chung and Hoag, 1990), we let an increase in demand trigger the merger. Only after demand has been increased does the reduction in marginal cost motivate the cost of restructuring. Firms are assumed to respond quickly to the shock ( $\mu$ high) so that $W_{z}$ reflects expectations of the merger. Assume the merger to be anticompetitive, ie $\pi_{z}^{-}>\pi_{z}$. The competitor's stock market value is nevertheless reduced if being an outsider is significantly worse than being an insider. To construct this example, the reduction in marginal cost must be sufficiently 
large to make it better to be an insider than an outsider, but sufficiently small to guarantee that the merger is anti-competitive.

\subsection{Event Windows}

So far, we have only discussed the change in value at the point in time of the merger announcement. In practice, the change is measured over a short period of time around the event. This creates an additional complication, namely that there is a positive probability that the shock is included in the event window, in which case the observed change is $\Delta W^{\text {merger }}+\Delta W^{\text {shock }}=$ $\left(W_{z}^{-}-W_{z}\right)+\left(W_{z}-W_{y}\right)$, but also that it is not, in which case the observed change is given by $\Delta W^{\text {merger }}=W_{z}^{-}-W_{z}$ as before. The shock will be included in an event window of length $\omega$ with probability

$$
G(\omega / 2)=1-e^{-\mu(\omega / 2)},
$$

as shown in Lemma 3 (in Appendix A). This probability is determined by the length of the event window $(\omega)$, relative to the expected time between the shock and the merger $(1 / \mu)$.

Proposition 2 Assume there to be a merger race subsequent to the shock (inequality 7), but that firms do not bid prior to the shock (inequality 8). If the shock is included in the event window, the observed change in the outsider's stock-market value is given by

$$
\begin{aligned}
\Delta W^{\text {merger }}+\Delta W^{\text {shock }}= & \left(1-\frac{\lambda}{\lambda+r} \frac{\mu}{r+\mu}\right) \underbrace{\left(\pi_{z}^{-}-\pi_{z}\right) / r}_{\text {profit effect }}-\frac{\lambda}{\lambda+r} \frac{\mu}{r+\mu} \underbrace{\frac{2}{3}\left(\pi_{z}^{+} / 2-\pi_{z}^{-}\right) / r}_{\text {out-of-play effect }}+ \\
& +\frac{r}{\lambda+r} \underbrace{\left(\pi_{z}-\pi_{y}\right) / r}_{\text {trigger effect }} .
\end{aligned}
$$


The change in the share prices now also includes a trigger effect, which captures the effect of the change in the market conditions provoking the merger. It is measured by the change in triopoly profits, ie $\left(\pi_{z}-\pi_{y}\right) / r$. Whether the trigger effect tends to increase or decrease the outsider's share prices depends on the nature of the shock. For example, the trigger effect will be positive if the merger is triggered by an increase in demand. ${ }^{13}$

It is easily demonstrated by way of example that:

Corollary 2 (a) A pro-competitive merger may increase the stock market value of a competitor.

Corollaries 1 (b) and 2 (a) demonstrate that there does not exist a simple relation between changes in the outsider's stock market value and the competitive effects of a merger. As argued below, however, the problem with the trigger effect may not be severe, if the use of abnormal returns is an effective way of controlling for confounding events.

To construct an example, assume the market to be described by the same Cournot model as in Corollary 1 (b). Consider a pro-competitive merger, ie a merger reducing the competitor's profit, $\pi_{z}^{-}<\pi_{z}$. The competitor's stock market value is nevertheless increased if the shock increases (triopoly) profits, and if this increase is larger than the reduction in profits as a result of the merger, assuming that the shock was unlikely to occur in the near future (ie a low $\lambda)$.

One of the advantages with event studies is that share prices need only be observed during a relatively short event window. The event under study may

\footnotetext{
${ }^{13}$ Introducing an event window does not affect Corollary 1 (a). When firms respond very slowly to the shock $(\mu \rightarrow 0)$, an event study at the merger announcement identifies the competitive effect, since in this case the shock will not be included in the event window, and $\Delta W^{\text {merger }}=W_{z}^{-}-W_{z}$ with probability one.
} 
thus be isolated from other events affecting the firms' performance. It may be conjectured that the trigger-effect will disappear, if the event window is made small ( $\omega \rightarrow 0$ ) so that the shock is excluded from it with high probability. This conjecture is proven correct in the present model, as revealed by a comparison between Proposition 1, where the shock is excluded from the window, and Proposition 2, where it is included. Surprisingly, however, such a reduction of the event window may be counter productive.

Corollary 2 (b) If the triggering shock is excluded from the event window, the weight on the profit effect is given by $\frac{r}{r+\mu}=1-\frac{\mu}{r+\mu}$, which is lower than the weight on the profit effect in case the triggering shock is included, ie $1-\frac{\lambda}{\lambda+r} \frac{\mu}{r+\mu}$.

To understand this result, note that the change in value at the time of the shock is

$$
\Delta W^{\text {shock }}=W_{z}-W_{y}=\frac{r}{\lambda+r}\left[\left(\pi_{z}-\pi_{y}\right)+\frac{\mu}{r+\mu}\left(\pi_{z}^{+}+\pi_{z}^{-}-3 \pi_{z}\right) / 3\right] / r .
$$

The second term captures the fact that the market is informed that the merger is now more likely to occur in the near future. It can be decomposed into two terms,

$$
\left(\pi_{z}^{+}+\pi_{z}^{-}-3 \pi_{z}\right) / 3=\left(\pi_{z}^{-}-\pi_{z}\right)+\frac{2}{3}\left(\pi_{z}^{+} / 2-\pi_{z}^{-}\right)
$$

ie the increase in profit if the firm were to become an outsider, plus the additional increase due to the possibility of becoming an insider rather than an outsider. Thus, adding $\Delta W^{\text {shock }}$ to $\Delta W^{\text {merger }}$ (given in Proposition 1) increases the weight on the profit effect and reduces the (negative) weight on the out-of-play effect. Intuitively, by not including the shock in the window, 
we only observe the expectations to become an insider burst. Including the shock, we also observe the formation of (part of) these expectations. The second effect partly offsets the first, thereby reducing the weight on the outof-play term. In contrast, the shock reinforces the profit effect.

\subsection{Robustness of the Out-of-Play Effect}

Symmetry The out-of-play effect crucially hinges on the assumption that the market anticipates a merger, but is uncertain about the allocation of the roles of acquirer, target and outsider. There are good reasons to believe that uncertainty about the allocation of roles in an anticipated merger is a robust phenomenon. When it is better to be an insider than an outsider, there does not exist any asymmetric equilibria with a predetermined allocation of roles. If a firm were to be selected as outsider, its stock-market value before the merger would be lower than the other firms' values, implying that this firm would be the best buy.

Uncertainty about the allocation of roles also survives the introduction of asymmetries between the firms (Fridolfsson, 2001). In this case, the market may have partial information about the likely target and the likely acquirer, but the remaining uncertainty about roles still implies an out-of-play effect. For mergers that are expected with a high probability, the effect will be small, but for mergers that are expected with a low probability the effect will be large. The out-of-play effect will be absent only if firms are sufficiently different so that the allocation of roles in equilibrium is done with certainty. ${ }^{14}$

If firms differ to a sufficient extent, the equilibrium allocation of roles

\footnotetext{
${ }^{14} \mathrm{~A}$ concrete illustration of why the out-of-play effect is not a knife-edge result is if there is a marginal cost synergy only if firms $A$ and $B$ merge. Then, the profit motive for $A$ and $B$ to merge would be larger than in other mergers. But firm $C$ may have a strong preemption motive for acquiring one of the rivals first.
} 
may be certain, however. For example, in the battle between Vodafone and Cingular to take over AT\&T Wireless, other potential acquirers, eg NTT DoCoMo, were reported to have withdrawn from the battle. In such a case, event studies may simply focus on the firms which are not potential targets or acquirers to assess the competitive nature of the merger.

Bidding technology We have assumed that bidding opportunities arise exogenously for the firms with hazard rate $\mu$. This assumption is interpreted as a reduced form, ie as the outcome of a symmetric equilibrium in some non-cooperative game where firms choose their $\mu_{i}$ 's.

In a more complex model where firms choose different "bidding intensities," eg as a result of different managerial efficiency, losing a merger race may work as a signal to the market about inferior efficiency and, thus, result in an additional reduction in the outsider's stock market value.

We have also assumed the expected time before the first bid to be the same as the expected time before the second bid. Our results would not change if we instead assumed the first bid to be followed by a fast Rubinstein-Ståhl bargaining game between the acquirer and the target. Only the distribution of the surplus between the two insiders would be affected.

Private information We have assumed the firms and the stock market to have the same information about eg merger efficiencies. In the presence of private information, the exact form of the firms' objectives becomes important. If firms maximize their expected discounted future profit stream, given their own superior information, at least one new aspect arises, namely that the merger announcement will contain information about the size of the efficiency gains. If firms maximize their stock market value, ie the expected discounted future profit stream, given the publicly available information, sig- 
nalling efficiency gains may even become a motive for merger.

Investor risk preferences The equilibrium stock market value of a firm has been assumed to equal the expected discounted value of future profits. Since there is uncertainty about the exact timing of a merger and about the allocation of roles in a future merger, the investors' risk-preferences may be of importance. In the present paper, however, we assume firms to be identical. Therefore, investors can insure themselves against risk associated with the allocation of roles, simply by holding a portfolio with equal amounts of the three firms.

An interesting issue for future research is to investigate whether the uncertainty about roles will reduce equilibrium pre-merger share-prices in case firms are asymmetric and investors risk-averse. If so, the merger announcement will be associated with an additional effect on share prices related to the resolution of the risk in the allocation of roles.

\section{Potential Solutions}

While Propositions 1 and 2 identify three sources of mis-specification in event studies of rivals' returns, the conclusion that stock market evidence cannot be used to detect the competitive nature of mergers is certainly premature. For instance, Banerjee and Eckard (1998) were aware of out-of-play effects before us, and even attempt to control for them. Defining the first rumor of the merger in the business press as the event (rather than the merger announcement), they make it unlikely that the consolidations were anticipated. In section 4.1 , we argue that the merits of this first-rumor methodology depend on the exact contents of the rumors.

Moreover, Corollary (b) to Proposition 2 does not imply that event win- 
dows should be made long. Using a short event window still has the advantage of reducing the effect of confounding events. The Proposition suggests, however, a new consideration in the choice of the length of the event window, and in section 4.2 we further discuss the pros and cons of long event windows.

\subsection{First Rumor}

Rumors with uncertainty about roles First, consider the case when the first rumor creates anticipations about a merger, but the allocation of roles remains uncertain. To analyze the role of such a first rumor, we model it as an "information shock." Let there be an initial state $x$ where firms' profits are the same as in state $y$, but where the agents are unaware that the market may be hit by a shock to profits. At the time of the information shock (transition from $x$ to $y$ ), all agents learn that a market shock (transition from $y$ to $z$ ) will occur in the future. The stock market value of a triopoly firm in state $x$ is given by $W_{x}=\pi_{y} / r$, since the stock market does not anticipate any market shock or merger. ${ }^{15}$ After the information shock, the firms' stock market value is given by $W_{y}$, defined above. We continue to assume there to be a merger race subsequent to the market shock, but that firms do not bid prior to the shock.

Assume now that an event study of the rival's returns is carried out at the first rumor, and that the market shock is not included in the event window.

\footnotetext{
${ }^{15}$ For simplicity, we also assume agents in $x$ to be unaware of the possible transition to $y$. We have, however, worked out a model with rational expectations also in $x$, assuming common knowledge of a constant hazard rate $\lambda^{\prime} \approx 0$ to enter state $y$. As the more complex model delivers the same results, it is not used here.
} 
Then,

$$
\Delta W^{\text {rumor }}=W_{y}-W_{x}=\frac{\lambda}{\lambda+r}\left[\left(\pi_{z}-\pi_{y}\right)+\frac{\mu}{r+\mu}\left(\pi_{z}^{+}+\pi_{z}^{-}-3 \pi_{z}\right) / 3\right] / r,
$$

is observed, which does not capture the competitive effects of the future merger. Rather, this difference captures the newly formed expectation that a shock will affect profits in the future, and that a merger (with unknown roles) will change the aggregate industry profits in an even more distant future.

Rumors about a specific merger Next, consider rumors that a specific merger is likely to occur. In the absence of any previous rumors of a merger (with uncertainty about the allocation of roles), an event study at the time of the rumor will not be affected by any out-of-play effects. A problem with this method is that a trigger effect will be included, in case confounding events are not efficiently controlled for. Moreover, if the presumption is false (ie there have been previous rumors of a merger with uncertainty about the allocation of roles), the first-rumor method will include an out-of-play effect.

In fact, an event study at the time of the merger announcement may be preferred. It will, with certainty, not include an out-of-play effect, ie no presumptions are needed. Another advantage of running the event study at the announcement is that it is unlikely to include a trigger effect, if the window is short. ${ }^{16}$

\footnotetext{
${ }^{16}$ Banerjee and Eckard argue that their method works in their particular sample, since there are only insignificant movements in the share prices in the two months before the event, indicating that no anticipations were formed in that period. This test is not conclusive, however, since other event studies find evidence of anticipations being formed over much longer periods than two months (see eg Bradley, Desai and Kim, 1983, and Asquith, 1983). Moreover, substantial empirical evidence indicates that some mergers are unprofitable and may solely be motivated by preemption (Fridolfsson and Stennek,
} 
The general conclusion from this discussion is that event studies are sensitive to the exact anticipations and uncertainties present in the stock market prior to the merger. This suggests that the tests must be adapted to the special circumstances in each different merger, and each different outsider.

\subsection{Long Windows}

There is, however, a possibility of eliminating the out-of-play effect by carrying out an event study of rivals' returns with a sufficiently long window to include all three events, ie first rumor, market shock and merger announcement. Consider again the case when the first rumor creates anticipations about a merger, but the allocation of roles remains uncertain. The observed change over the extended window is then given by

$$
\Delta W^{\text {merger }}+\Delta W^{\text {shock }}+\Delta W^{\text {rumor }}=\underbrace{\left(\pi_{z}^{-}-\pi_{z}\right) / r}_{\text {Profit effect }}+\underbrace{\left(\pi_{z}-\pi_{y}\right) / r}_{\text {Trigger effect }} .
$$

Even though the out-of-play effect is absent from equation (14), the profit effect is still not identified, due to the trigger effect.

The trigger effect is an instance of the classical statistical endogeneity problem. Since there is an unobserved variable (eg the level of demand) which is correlated with the explanatory variable (ie the occurrence of merger), the latter will be correlated with the error term. Using a measure of cumulative abnormal return (CAR), defined as the actual return of the security over the event window minus the normal return of the firm over the event window is a commonly used technique for separating out confounding events. The normal return, defined as the expected return without conditioning on the

2000). For these mergers, the share prices for both insiders and outsiders are reduced when anticipations are formed. 
event taking place, may eg be estimated using a linear model relating the return of the security to the return of the market portfolio (see eg MacKinlay, 1997). It is easily seen that this methodology can also be applied in the present context. Assume that the control firms (in the market portfolio) are affected in the same way by the shock as the outsider, ie $\tilde{\pi}_{z}-\tilde{\pi}_{y}=\pi_{z}-\pi_{y}$, then the change in the market portfolio, at the time of the information shock, is given by $\Delta \widetilde{W}^{\text {rumor }}=\widetilde{W}_{y}-\widetilde{W}_{x}=\frac{\lambda}{\lambda+r}\left(\pi_{z}-\pi_{y}\right)$, at the time of the shock it is given by $\Delta \widetilde{W}^{\text {shock }}=\widetilde{W}_{z}-\widetilde{W}_{y}=\frac{r}{\lambda+r}\left(\pi_{z}-\pi_{y}\right)$, and it is unaffected at the time of the merger announcement, $\Delta \widetilde{W}^{\text {merger }}=0$. Thus: Assume there to be a merger race subsequent to the shock (inequality 7), but that firms do not bid prior to the shock (inequality 8). Then, an event study of the rival's returns with a sufficiently long window to include both the first rumor and the announcement will observe

$\Delta W^{\text {merger }}+\Delta W^{\text {shock }}+\Delta W^{\text {rumor }}-\Delta \widetilde{W}^{\text {merger }}-\Delta \widetilde{W}^{\text {shock }}-\Delta \widetilde{W}^{\text {rumor }}=\left(\pi_{z}^{-}-\pi_{z}\right) / r$.

Thus, the competitive effect of the merger is identified.

We see this result as a mere "proof of principle," however. In case measuring abnormal returns succeeds in eliminating the trigger effect, using a long window (equation 15) is clearly preferable to using a short one (Proposition 1). Otherwise, there is a trade-off depending on the relative strength of the out-of-play effect and the trigger effect. While measuring abnormal returns may be useful for eliminating eg variations in the economy wide investment climate, there is no guarantee that comparisons with the market portfolio eliminate the effects of the shocks triggering a merger, since such shocks may be specific to the product and the geographical market where the firms operate. A possible way out of this problem is to compare the outsider's stock 
market value with a more narrow sample of firms operating on the same product market or the same geographical market. The additional problem is then to ensure that these control firms are not themselves exposed to an externality from the merger.

\subsection{Corporate Customers}

More recently an alternative event study approach has been devised to identify competitive effects. The idea, initially proposed by Mullin, Mullin and Mullin (1995), is to investigate the wealth effects on corporate customers. This development is important for two reasons. First, it offers an alternative approach which appears to focus more directly on mergers' competitive effects. Second, by including both rivals and customers in the same sample, the rivals'-returns-methodology may be validated; this is still important since not all firms sell to corporate customers.

Using this method, Fee and Thomas (2004) and Shahrur (2005) demonstrate that rivals' share prices on average are increased at the merger announcement, but that the effects on customers are insignificant. They conclude that the evidence is suggestive of in-play effects, thus reinforcing the critique of the rivals' returns method. The same basic idea could potentially also shed some light on out-of-play effects. A pattern consistent with the presence of such effects would be if rivals earn negative returns in subsamples where corporate customers do.

It should be noted, however, that also event studies on corporate customers may fail to capture a merger's competitive effects. When corporate customers use the merging firms' product as an intermediate good, they often compete against each other in a downstream market. If the demand in this latter market is inelastic, a higher input price may induce the corpo- 
rate customers' to charge higher markups and thereby increase their profits (Kimmel, 1992). ${ }^{17}$

\section{Conclusion}

We show that anti-competitive mergers may reduce competitors' share prices, despite increasing their profits. Thus, we provide a possible reconciliation of the diverging empirical evidence on the welfare effects of horizontal mergers.

One condition for this phenomenon is that mergers both reduce competition and generate efficiencies, and that the net effect is to increase rivals' profits while still increasing the participants' profits even further. In the equilibrium of the acquisition game, firms compete to acquire their competitors. The stock market is efficient and the pre-merger share prices reflect anticipations of a merger, but uncertainty about the merger participants remains. When one merger occurs, the market is informed that other alternatives become impossible, that is, the merger announcement informs the market that formerly potential targets and acquirers are now out of play.

Our critique of event studies of rivals' returns is not of academic interest only, since the results are used in the public debate to evaluate merger policy. The question is whether competition authorities can identify and prohibit anti-competitive mergers, while clearing pro-competitive ones? Much of the evidence has been interpreted to be consistent with the efficiency hypothesis. Thus, Eckbo and Wier (1985) argue that "all but the 'most overwhelmingly large' mergers should be allowed to go forward." Neven and Röller (2002) study the first ten years of EU merger control and show that the European Commission has allowed several mergers, even though the rivals' returns sug-

\footnotetext{
${ }^{17}$ This observation also implies that corporate customers' testimonies in antitrust cases may be misleading as emphasized by Farrell (2004).
} 
gest them to be anti-competitive. They also suggest possible policy reforms to address this issue.

There are many good reasons for continuing to use event studies. Stock market data are readily available, and can be used to evaluate mergers before competition authorities intervene; they may even be used to assess the competitive effects of proposed mergers that were later blocked and thus, never occurred. One must also bear in mind that the alternative methods for assessing the same issues are not devoid of problems. For this reason, we have also demonstrated how the out-of-play effect may be eliminated by an adaptation of the methodology, combining evidence from the first rumor with evidence from the merger announcement.

\section{References}

Acharya, Sankarchan: A Gerneralized Econometric Model and Tests of a Signalling Hypothesis with Two Discrete Signals, The Journal of Finance, Vol. XLIII No. 2 (June 1988), pp. 413- 429.

Acharya, Sankarchan: Value of Latent Information: Alternative Event Study Methods, The Journal of Finance, Vol. XLVIII No. 1 (March 1993), pp. 363- 385 .

Asquith, Paul: Merger Bids, Market Uncertainty, and Stockholder Returns, Journal of Financial Economics; 11(1-4), April 1983.

Banerjee, Ajeyo; Eckard, Woodrow E: Are Mega-Mergers Anti-competitive? Evidence from the First Great Merger Wave, Rand Journal of Economics; 29(4), Winter 1998, 803-27.

Barton, David M.; Sherman, Roger: The Price and Profit Effects of Horizontal Merger: A Case Study, Journal of Industrial Economics, 33(2), 
$1984,165-77$.

Borenstein, Severin: Airline Mergers, Airport Dominance, and Market Power, American Economic Review, Papers and Proceedings 80(2), May 1990, 400-404.

Bradley, Michael; Desai, Anand; Kim, E. Han: The Rationale behind Interfirm Tender Offers, Journal of Financial Economics; 11(1-4), April 1983.

Dixit, Avinash: Investment and Hysteresis, Journal of Economic Perspectives v6, n1 (Winter 1992): 107-32.

Eckbo, B. Espen: Horizontal Mergers, Collusion, and Stockholder Wealth, Journal of Financial Economics; 11(1-4), April 1983.

Dafny, Leemore: Estimation and Identification of Merger Effects: An Application to Hospital Mergers, NBER Working Paper No. W11673, 2005 .

Deneckere, Raymond; Davidson, Carl: Incentives to Form Coalitions with Bertrand Competition, Rand Journal of Economics; 16(4), Winter $1985,473-86$.

Dutz, Mark A.: Horizontal Mergers in Declining Industries: Theory and Evidence, International Journal of Industrial Organization v7, n1 (Special Issue, March 1989): 11-33.

Eckbo, B. Espen; Wier, P: Antimerger Policy under the Hart-Scott-Rodino Act: A Reexamination of the Market Power Hypothesis, Journal of Law and Economics; (28) 1985, 119- 49. 
Eckbo, B. Espen; Maksimovic, Vojislav; Williams, Joseph: Consistent Estimation of Cross-Sectional Models of Event Studies, The Review of Financial Studies, Vol. 3, No. 3. (1990), pp. 343-365.

Fabozzi, Frank J.; Ferri, Michael G.; Fabozzi, T. Dessa; Tucker Julia: A Note on Unsuccessful Tender Offers and Stockholder Returns, Journal of Financial Economics; Vol XLIII, No 5, December 1988.

Farrell, Joseph: Listening to Interested Parties in Antitrust Investigations: Competitors, Customers, Complementors and Relativity, Antitrust, 18(2), Spring 2004, 64-68.

Farrell, Joseph and Carl Shapiro: Horizontal Mergers: An Equilibrium Analysis, American Economic Review; 80(1), March 1990, 107-26.

Fee, C. Edward and Shawn Thomas: Sources of Gains in Horizontal Mergers: Evidence from Customer, Supplier, and Rival Firms, Journal of Financial Economics 74 (2004): 423-460.

Focarelli, Dario and Fabio Panetta: Are Mergers Beneficial to Consumers? Evidence from the Market for Bank Deposits, American Economic Review 93 (4), September 2003, 1152-1171.

Fridolfsson, Sven-Olof: Essays on Endogenous Merger Theory, Dissertations in Economics, Stockholm University, 2001:1.

Fridolfsson, Sven-Olof; Stennek, Johan: Why Mergers Reduce Profits, and Raise Share Prices-A Theory of Preemptive Mergers, Journal of the European Economic Association, Septembler 2005, 3(5):1083-1104.

Heckman, James J. ; Smith, Jeffrey A.: The Pre-programme Earnings Dip and the Determinants of Participation in a Social Programme. Implica- 
tions for Simple Programme Evaluation Strategies, Economic Journal v109, n457 (July 1999): 313-48.

Horn, Henrik; Persson, Lars: Endogenous Mergers in Concentrated Markets, International Journal of Industrial Organization v19, n8 (September 2001a): 1213-44.

Horn, Henrik; Persson, Lars: The Equilibrium Ownership of an International Oligopoly, Journal of International Economics 53(2), April 2001b, 307-33.

Jovanovic, Boyan; Rousseau, Peter L.: Mergers and Technological Change: 1885-1998, mimeo. University of Chicago.

Kamien, Morton I.; Zang, Israel: The Limits of Monopolization through Acquisition, Quarterly Journal of Economics; 105(2), May 1990, 46599.

Kamien, Morton I.; Zang, Israel: Monopolization by Sequential Acquisition, Journal of Law, Economics and Organization; 9(2),October 1993, 20529.

Kim, E. Han; Singal, Vijay: Mergers and Market Power: Evidence from the Airline Industry, American Economic Review; 83(3), June 1993, $549-69$.

Kimmel,Sheldon: Effects of Cost Changes on Oligopolists' Profits, The Journal of Industrial Economics, 40(4), December 1992, 441-449.

MacKinlay, A. Craig: Event Studies in Economics and Finance, Journal of Economic Literature, vol. XXXV (March 1997), pp.13-39. 
McAfee, R. Preston; Williams, Michael A.: Can Event studies Detect Anticompetitive Mergers?, Economics Letters; 28(2), 1988, 199-203.

Mitchell, Mark L.; Mulherin, J. Harold: The Impact of Industry Shocks on Takeover and Restructuring Activity, Journal of Financial Economics 41(2), June 1996, 193-229.

Mueller, Dennis C.: Mergers and Market Share, Review of Economics and Statistics; 67(2), May 1985, 259-67.

Mullin, George L.; Mullin, Joseph C.; Mullin, Wallace P.: The Competitive Effects of Mergers: Stock Market Evidence from the U.S. Steel Dissolution Suit, RANDJournalofEconomics v26, n2 (Summer 1995): 314-30.

Neven, J. Damien; and Röller, Lars-Hendrik: Discrepancies between Markets and Regulators: An Analysis of the First Ten Years of EU Merger Control, in The Pros and Cons of Merger Control, Swedish Competition Authority (Konkurrensverket), Stockholm, 2002, 13-38.

Perry, Martin K.; Porter, Robert H.: Oligopoly and the Incentive for Horizontal Merger, American Economic Review; 75(1), March 1985, 219-27.

Prabhala, N. R.: Conditional Methods in Event Studies and an Equilibrium Justification for Standard Event-Study Procedures, The Review of Financial Studies Vol. 10, No. 1. (Spring 1997), pp. 1-38.

Prager, Robin A. and Hannan, Timothy H.: Do Substantial Horizontal Mergers Generate Significan Price Effects? Evidence from the Banking Industry, Journal of Industrial Economics 46 (4), December 1998, 433452. 
Roll, Richard: Empirical Evidence on Takeover Activity and Shareholder Wealth, in Modern Finance $\&$ Industrial Economics, Thomas E. Copeland, ed., New York: Basil Blackwell, 1987, 74-91.

Salant, Stephen W.; Switzer, Sheldon; Reynolds, Robert J.: Losses from Horizontal Merger: The Effects of an Exogenous Change in Industry Structure on Cournot-Nash Equilibrium, Quarterly Journal of Economics; 98(2), May 1983, 185-99.

Schumann, Laurence: Patterns of Abnormal Returns and the Competitive Effects of Horizontal Mergers, Review of Industrial Organization; 8(6), December 1993, 679-96.

Shahrur, Husayn: Industry Structure and Horizontal Takeovers: Analysis of Wealth Effects on Rivals, Suppliers, and Corporate Customers, Journal of Financial Economics 76, 2005, 61-98.

Singal, Vijay: Airline Mergers and Competition: An Integration of Stock and Product Price Effects, Journal of Business; 69(2), 1996.

Song, Moon H., and Ralph A. Walkling: Abnormal Returns to Rivals of Acquisition Targets: A Test of the "Acquisition Probability Hypothesis," Journal of Finacial Economics 55, 2000, 143-171.

Stigler, George J.: Monopoly and Oligopoly by Merger, American Economic Review, Papers and Proceedings 40, 1950, 23-34.

Stillman, Robert: Examining Antitrust Policy toward Horizontal Mergers, Journal of Financial Economics;11(1-4), April 1983.

Werden, Gregory J., Joskow, Andrew S. and Johnson, Richard: The Effects of Mergers on Price and Output: Two Case Studies from the Airline 
Industry, Managerial and Decision Economics 12, 1991, 341-352.

Weston, J. Fred; Chung, Kwang S.; Hoag, Susan E.: Mergers, Restructuring, and Corporate Control, Prentice Hall, Englewood Cliffs, NJ, 1990.

\section{A Proofs}

\section{A.1 Lemma 1}

Lemma 1 Consider the set of symmetric Markov perfect equilibria in a subgame starting after the shock has occurred. There is a merger race equilibrium iff $\frac{r}{r+\mu}\left(\pi_{z}^{+} / 2-\pi_{z}\right)+\frac{\mu}{r+\mu}\left(\pi_{z}^{+} / 2-\pi_{z}^{-}\right) / 3 \geq 0$; otherwise, there is a merger hold-up equilibrium. In case of a race, the pre-merger share price is given by $W_{z}=\left[\frac{r}{r+\mu} \pi_{z}+\frac{\mu}{r+\mu}\left(\pi_{z}^{+}+\pi_{z}^{-}\right) / 3\right] / r$, and otherwise by $W_{z}=\pi_{z}^{+} / 2 r$.

Proof: The proof of Lemma 1 is constructed essentially using two expressions. Condition (1) describes the acquisition-game equilibrium, defining $p_{z}$ as a function of $W_{z}$ and the oligopoly profit levels. Equation (5) describes the stock-market equilibrium, defining $W_{z}$ as a function of $p_{z}$ and the oligopoly profit levels.

First, consider a merger race equilibrium in state $z$, ie $p_{z}=1 / 2$. Then, by equations (2), (4) and (5):

$$
W_{z}=\left[\frac{r}{r+\mu} \pi_{z}+\frac{\mu}{r+\mu}\left(\pi_{z}^{+}+\pi_{z}^{-}\right) / 3\right] / r
$$

By condition (1), there is a merger race iff $W_{z}^{+} \geq 2 W_{z}$ or, equivalently, $\frac{r}{r+\mu}\left(\pi_{z}^{+} / 2-\pi_{z}\right)+\frac{\mu}{r+\mu}\left(\pi_{z}^{+} / 2-\pi_{z}^{-}\right) / 3 \geq 0$.

Second, consider an equilibrium with hold-up in state $z$, ie $p_{z} \in(0,1 / 2)$. 
Then, by condition (1) and the definition of $W_{z}^{+}$,

$$
W_{z}=\pi_{z}^{+} / 2 r
$$

which is used to eliminate $W_{z}$ in (4) and (5). Inserting the value of $V_{z}$ into equation (5) and solving for $p_{z}$ yields $p_{z}=-\frac{3 r}{2 \mu}\left(\frac{\pi_{z}^{+} / 2-\pi_{z}}{\pi_{z}^{+} / 2-\pi_{z}^{-}}\right)$in the generic case when $\pi_{z}^{+} / 2 \neq \pi_{z}^{-}$. Note that $p_{z}>0$ iff $\pi_{z}^{+} / 2<\pi_{z}^{-}$, since $\pi_{z}^{+} / 2>\pi_{z}$. Moreover, if $\pi_{z}^{+} / 2<\pi_{z}^{-}$, then $p_{z}<1 / 2$ iff $\frac{r}{r+\mu}\left(\pi_{z}^{+} / 2-\pi_{z}\right)+\frac{\mu}{r+\mu}\left(\pi_{z}^{+} / 2-\pi_{z}^{-}\right) / 3<$ 0 . Note that this condition is the reverse of the condition for the existence of a merger race equilibrium.

Third, consider an equilibrium with no mergers in state $z$, ie $p_{z}=0$. Then, by equations (4) and (5):

$$
W_{z}=\pi_{z} / r
$$

A merger does not occur iff $W_{z}^{+} \leq 2 W_{z}$, or equivalently $\pi_{z}^{+} \leq 2 \pi_{z}$, thereby violating the assumption that mergers are profitable in state $z$. QED.

\section{A.2 Lemma 2}

Lemma 2 Assume that $\pi_{y}^{+} / 2<\pi_{y}^{-}$, and consider the set of symmetric Markov perfect equilibria in state $y$.

1. Assume there to be a merger hold-up equilibrium in state z. Then, no merger occurs in state $y$.

2. Assume there to be a merger race equilibrium in state z. There exists two threshold values $\lambda_{\text {NoMerger }}>0$ and $\lambda_{\text {Race }}>0$ such that: there is a no merger equilibrium in state $y$ iff $\lambda \leq \lambda_{\text {NoMerger }}$; there is a merger 
race equilibrium in state $y$ iff $\lambda \geq \lambda_{\text {Race }}$; there is a merger hold-up equilibrium in state $y$ iff $\lambda \in\left(\lambda_{\text {NoMerger }}, \lambda_{\text {Race }}\right)$ or $\lambda \in\left(\lambda_{\text {Race }}, \lambda_{\text {NoMerger }}\right)$. If there is a no merger equilibrium in $y, W_{y}=\left[\frac{r}{\lambda+r} \pi_{y}+\frac{\lambda}{\lambda+r}\left(\frac{r}{r+\mu} \pi_{z}+\frac{\mu}{r+\mu}\left(\pi_{z}^{+}+\pi_{z}^{-}\right) / 3\right)\right] / r$.

Proof: The basic idea in the proof of Lemma 2 is the same as in the proof of Lemma 1, but the algebra is less transparent. Condition (1) describes the acquisition-game equilibrium, defining $p_{y}$ as a function of $W_{y}$ and the oligopoly profit levels. Equation (6) describes the stock-market equilibrium, defining $W_{y}$ as a function of $p_{y}$ and the oligopoly profit levels. The most important difference to the proof of Lemma 1 is that firms' stock-market values in $y$, ie $W_{y}$, are also a function of the equilibrium in state $z$, since $V_{z}$ enters equation (6). To overcome this difficulty, we start the proof by rewriting equation (6) in the following way

$$
\begin{aligned}
W_{y}= & \frac{\lambda}{\lambda+r+\mu} W_{z} \\
& +\frac{r+\mu}{\lambda+r+\mu}\left\{\frac{r}{r+\mu} \pi_{y} / r+\frac{\mu}{r+\mu}\left[\frac{2}{3} p_{y}\left(\frac{r}{r+\lambda}\left(\pi_{y}^{+}+\pi_{y}^{-}\right)+\frac{\lambda}{r+\lambda}\left(\pi_{z}^{+}+\pi_{z}^{-}\right)\right)+\left(1-2 p_{y}\right) W_{y}\right]\right\},
\end{aligned}
$$

where we have used equation (3), noting that the first term in (6) equals $\frac{\lambda}{\lambda+r+\mu} W_{z}$, as well as equations (4) and (5).

Proof of point 1: By Lemma 1, $W_{z}=\pi_{z}^{+} / 2 r$ and $\frac{r}{r+\mu}\left(\pi_{z}^{+} / 2-\pi_{z}\right)+\frac{\mu}{r+\mu}\left(\pi_{z}^{+} / 2-\pi_{z}^{-}\right) / 3<$ 0 , when there is a hold-up equilibrium in state $z$. Note that the inequality implies that $\pi_{z}^{+} / 2-\pi_{z}^{-}<0$, since $\pi_{z}^{+} / 2>\pi_{z}$.

First, consider an equilibrium with no mergers in $y$, ie $p_{y}=0$. Since $W_{z}=\pi_{z}^{+} / 2 r$, equation (6') may be rewritten as

$$
W_{y}=\left[\frac{r}{\lambda+r} \pi_{y}+\frac{\lambda}{\lambda+r} \pi_{z}^{+} / 2\right] / r
$$

According to condition (1), no merger occurs in state $y$ iff $W_{y}^{+} \leq 2 W_{y}$, or 
equivalently $\pi_{y}^{+} \leq 2 \pi_{y}$, which is fulfilled by assumption.

Second, consider a merger race equilibrium in state $y$, ie $p_{y}=1 / 2$. Since $W_{z}=\pi_{z}^{+} / 2 r$, equation (6') may be rewritten as

$$
\begin{aligned}
W_{y}= & \frac{\lambda}{\lambda+r+\mu} \pi_{z}^{+} / 2 r+\frac{r}{\lambda+r+\mu} \pi_{y} / r \\
& +\frac{\mu}{\lambda+r+\mu}\left[\frac{r}{r+\lambda}\left(\pi_{y}^{+}+\pi_{y}^{-}\right)+\frac{\lambda}{r+\lambda}\left(\pi_{z}^{+}+\pi_{z}^{-}\right)\right] / 3 r .
\end{aligned}
$$

According to condition (1), there is a race in $y$ iff $W_{y}^{+} \geq 2 W_{y}$, or equivalently

$$
\frac{r}{r+\lambda}\left(\pi_{y}^{+} / 2-\pi_{y}^{-}\right)+\frac{\lambda}{r+\lambda}\left(\pi_{z}^{+} / 2-\pi_{z}^{-}\right) \geq-3\left(\pi_{y}^{+} / 2-\pi_{y}\right) r / \mu .
$$

This inequality is not fulfilled (since $\pi_{y}^{+} / 2<\pi_{y}^{-}, \pi_{z}^{+} / 2<\pi_{z}^{-}$and $\pi_{y}^{+} / 2<\pi_{y}$ ), thereby implying that a merger race equilibrium does not exist.

Third, consider an equilibrium with hold-up in state $y$, ie $p_{y} \in(0,1 / 2)$. Then, by equilibrium condition (1) and the definition of $W_{y}^{+}$,

$$
W_{y}=\frac{r}{r+\lambda} \pi_{y}^{+} / 2 r+\frac{\lambda}{r+\lambda} \pi_{z}^{+} / 2 r
$$

which is used to eliminate $W_{y}$ in $\left(6^{\prime}\right)$. Since $W_{z}=\pi_{z}^{+} / 2 r$, solving for $p_{y}$ in $(6 ')$ yields

$$
p_{y}=-\frac{3 r}{2 \mu} \frac{\pi_{y}^{+} / 2-\pi_{y}}{\frac{r}{r+\lambda}\left(\pi_{y}^{+} / 2-\pi_{y}^{-}\right)+\frac{\lambda}{r+\lambda}\left(\pi_{z}^{+} / 2-\pi_{z}^{-}\right)},
$$

for the generic case when $r\left(\pi_{y}^{+} / 2-\pi_{y}^{-}\right)+\lambda\left(\pi_{z}^{+} / 2-\pi_{z}^{-}\right) \neq 0$. Note that $p_{y}<0$, implying that a hold-up equilibrium does not exist, since $\pi_{y}^{+} / 2<\pi_{y}$, $\pi_{y}^{+} / 2<\pi_{y}^{-}$and $\pi_{z}^{+} / 2<\pi_{z}^{-}$.

Proof of point 2: By Lemma 1, $W_{z}=\frac{r}{r+\mu} \pi_{z} / r+\frac{\mu}{r+\mu}\left(\pi_{z}^{+}+\pi_{z}^{-}\right) / 3 r$ and $\frac{r}{r+\mu}\left(\pi_{z}^{+} / 2-\pi_{z}\right)+\frac{\mu}{r+\mu}\left(\pi_{z}^{+} / 2-\pi_{z}^{-}\right) / 3 \geq 0$, when there is a merger race equilibrium in $z$.

First, consider an equilibrium with no mergers in state $y$, ie $p_{y}=0$. 
Since $W_{z}=\frac{r}{r+\mu} \pi_{z} / r+\frac{\mu}{r+\mu}\left(\pi_{z}^{+}+\pi_{z}^{-}\right) / 3 r$, equation (6') may be rewritten as

$$
W_{y}=\left[\frac{r}{\lambda+r} \pi_{y}+\frac{\lambda}{\lambda+r}\left(\frac{r}{r+\mu} \pi_{z}+\frac{\mu}{r+\mu}\left(\pi_{z}^{+}+\pi_{z}^{-}\right) / 3\right)\right] / r
$$

According to condition (1), no merger occurs in state $y$ iff $W_{y}^{+} \leq 2 W_{y}$, or equivalently

$$
\begin{aligned}
& \frac{r}{r+\lambda}\left(\pi_{y}^{+} / 2-\pi_{y}\right)+\frac{\lambda}{r+\lambda}\left[\frac{r}{r+\mu}\left(\pi_{z}^{+} / 2-\pi_{z}\right)+\frac{\mu}{r+\mu} \frac{1}{3}\left(\pi_{z}^{+} / 2-\pi_{z}^{-}\right)\right] \leq 0 \\
\Leftrightarrow & \lambda \leq \lambda_{\text {NoMerger }} \equiv \frac{-r\left(\pi_{y}^{+} / 2-\pi_{y}\right)}{\frac{r}{r+\mu}\left(\pi_{z}^{+} / 2-\pi_{z}\right)+\frac{\mu}{r+\mu}\left(\pi_{z}^{+} / 2-\pi_{z}^{-}\right) / 3}
\end{aligned}
$$

where the denominator is positive, since $\frac{r}{r+\mu}\left(\pi_{z}^{+} / 2-\pi_{z}\right)+\frac{\mu}{r+\mu}\left(\pi_{z}^{+} / 2-\pi_{z}^{-}\right) / 3 \geq$ 0 when there is a merger race in $z$ (in the non-generic case when $\frac{r}{r+\mu}\left(\pi_{z}^{+} / 2-\pi_{z}\right)+$ $\frac{\mu}{r+\mu}\left(\pi_{z}^{+} / 2-\pi_{z}^{-}\right) / 3=0$, let $\left.\lambda_{\text {NoMerger }} \equiv+\infty\right)$.

Second, consider a merger race equilibrium in state $y$, ie $p_{y}=1 / 2$. Since $W_{z}=\frac{r}{r+\mu} \pi_{z} / r+\frac{\mu}{r+\mu}\left(\pi_{z}^{+}+\pi_{z}^{-}\right) / 3 r$, equation $\left(6^{\prime}\right)$ may be rewritten as

$$
\begin{aligned}
W_{y}= & \frac{\lambda}{\lambda+r+\mu}\left[\frac{r}{r+\mu} \pi_{z}+\frac{\mu}{r+\mu}\left(\pi_{z}^{+}+\pi_{z}^{-}\right) / 3\right] / r+\frac{r}{\lambda+r+\mu} \pi_{y} / r \\
& +\frac{\mu}{\lambda+r+\mu}\left[\frac{r}{r+\lambda}\left(\pi_{y}^{+}+\pi_{y}^{-}\right)+\frac{\lambda}{r+\lambda}\left(\pi_{z}^{+}+\pi_{z}^{-}\right)\right] / 3 r
\end{aligned}
$$

According to condition (1), there is a merger race in $y$ iff $W_{y}^{+} \geq 2 W_{y}$, or equivalently

$$
\begin{aligned}
& \frac{\mu}{\lambda+r+\mu}\left[\frac{r}{r+\lambda}\left(\pi_{y}^{+} / 2-\pi_{y}^{-}\right)+\frac{\lambda}{r+\lambda}\left(\pi_{z}^{+} / 2-\pi_{z}^{-}\right)\right] / 3 \\
& +\frac{r}{\lambda+r+\mu}\left(\pi_{y}^{+} / 2-\pi_{y}\right)+\frac{\lambda}{\lambda+r+\mu}\left[\frac{r}{r+\mu}\left(\pi_{z}^{+} / 2-\pi_{z}\right)+\frac{\mu}{r+\mu}\left(\pi_{z}^{+} / 2-\pi_{z}^{-}\right) / 3\right] \geq 0 \\
\Leftrightarrow & A \lambda^{2}+B \lambda+C \geq 0,
\end{aligned}
$$


where

$$
\begin{aligned}
& A=\frac{r}{r+\mu}\left(\pi_{z}^{+} / 2-\pi_{z}\right)+\frac{\mu}{r+\mu}\left(\pi_{z}^{+} / 2-\pi_{z}^{-}\right) / 3 \\
& B=r A+r\left(\pi_{y}^{+} / 2-\pi_{y}\right)+\mu\left(\pi_{z}^{+} / 2-\pi_{z}^{-}\right) / 3 \\
& C=r(3 r+\mu)\left(\pi_{y}^{+} / 2-\pi_{y}^{-}\right) / 3 .
\end{aligned}
$$

Note that the second-order polynomial in $\lambda$ is convex (since $A \geq 0$ when there is a merger race in $z)$ and strictly negative when $\lambda=0($ since $C<0)$. The polynomial thus has a strictly negative and a strictly positive root, and consequently the inequality is fulfilled for $\lambda>0$ iff $\lambda \geq \lambda_{\text {Race }}$, where $\lambda_{\text {Race }}$ is the positive root.

Third, consider an equilibrium with hold-up in state $y$, ie $p_{y} \in(0,1 / 2)$. Then, by equilibrium condition (1) and the definition of $W_{y}^{+}$,

$$
W_{y}=\left[\frac{r}{r+\lambda} \pi_{y}^{+}+\frac{\lambda}{r+\lambda} \pi_{z}^{+}\right] / 2 r
$$

which is used to eliminate $W_{y}$ in $\left(6^{\prime}\right)$. Since $W_{z}=\frac{r}{r+\mu} \pi_{z} / r+\frac{\mu}{r+\mu}\left(\pi_{z}^{+}+\pi_{z}^{-}\right) / 3 r$, solving for $p_{y}$ in (6) yields $p_{y}=N / D$ where

$$
\begin{aligned}
& N=-3\left[r\left(\pi_{y}^{+} / 2-\pi_{y}\right)+\lambda\left(\frac{r}{r+\mu}\left(\pi_{z}^{+} / 2-\pi_{z}\right)+\frac{\mu}{r+\mu} \frac{1}{3}\left(\pi_{z}^{+} / 2-\pi_{z}^{-}\right)\right)\right], \\
& D=2 \mu\left[\frac{r}{r+\lambda}\left(\pi_{y}^{+} / 2-\pi_{y}^{-}\right)+\frac{\lambda}{r+\lambda}\left(\pi_{z}^{+} / 2-\pi_{z}^{-}\right)\right]
\end{aligned}
$$

for the generic case when $\frac{r}{r+\lambda}\left(\pi_{y}^{+} / 2-\pi_{y}^{-}\right)+\frac{\lambda}{r+\lambda}\left(\pi_{z}^{+} / 2-\pi_{z}^{-}\right) \neq 0$. It remains to identify the conditions under which $p_{y} \in(0,1 / 2)$. Assume that $D<0$. Then $p_{y}>0$ iff $N<0$ and $p_{y}<1 / 2$ iff $2 N>D$. Note also that $N<0$ and $2 N>D$ imply that $D<0$. Hence, a hold-up equilibrium exists if $N<0$ and $2 N>D$. Analogously, it may be shown that a hold-up equilibrium exists if $N>0$ and $2 N<D$, by considering the case when $D>0$. Since we have considered all possibilities $(D<0$ and $D>0$ ), a hold-up equilibrium does 
not otherwise exist. Finally, note that

$$
\left\{\begin{array}{l}
N<0 \Leftrightarrow \lambda>\lambda_{\text {NoMerger }} \\
2 N>D \Leftrightarrow A \lambda^{2}+B \lambda+C<0 \Leftrightarrow \lambda<\lambda_{\text {Race }},
\end{array}\right.
$$

where $A, B$ and $C$ are defined as above. Hence, there is hold-up in $y$ iff $\lambda \in\left(\lambda_{\text {NoMerger }}, \lambda_{\text {Race }}\right)$ or $\lambda \in\left(\lambda_{\text {Race }}, \lambda_{\text {NoMerger }}\right)$. QED.

\section{A.3 Lemma 3}

Lemma 3 The probability that the shock is included in the event window is $G(\omega / 2)$

Proof: To compute the probability that the shock is included in an event window of length $\omega$, note that the event window starts at $t-\omega / 2$, where $t$ is the time of the merger. Let $s$ be the time of the shock, then the probability is given by $\operatorname{Pr}\{t-s<\omega / 2\}=G(\omega / 2)$, where the cumulative distribution function $G(\Delta)$ indicates the probability that (at any time) the next bidding round has occurred within $\Delta$ time units. QED.

\section{A.4 Proof of Proposition 1}

The stock-market reaction is given by $W_{z}^{-}-W_{z}$. By equation (2) and Lemma 1 ,

$$
W_{z}^{-}-W_{z}=\pi_{z}^{-} / r-\left[\frac{r}{r+\mu} \pi_{z}+\frac{\mu}{r+\mu}\left(\pi_{z}^{+}+\pi_{z}^{-}\right) / 3\right] / r .
$$

Simple algebra yields the desired result. QED. 


\section{A.5 Proof of Corollary 1 (b)}

The corollary is proved by way of example. Consider a linear homogenous good Cournot triopoly where inverse demand is given by $p=\alpha-\beta_{s} Q$. Assume the shock to be an increase in demand, ie $\beta_{y}>\beta_{z}$. In the triopoly, all firms have the same marginal cost, denoted $c<\alpha$. The equilibrium triopoly profits are given by

$$
\pi_{s}=\frac{1}{\beta_{s}}\left(\frac{\alpha-c}{4}\right)^{2} \equiv \frac{A^{2}}{\beta_{s}}
$$

If two firms merge, they restructure production, incurring a fixed $f$, thereby reducing the marginal cost by $d$. The marginal cost of an integrated entity is thus $c-d$. The equilibrium profits of an integrated insider and the outsider are given by

$$
\begin{aligned}
& \pi_{s}^{+}=\frac{1}{9 \beta_{s}}(4 A+2 d)^{2}-f, \quad \text { and } \\
& \pi_{s}^{-}=\frac{1}{9 \beta_{s}}(4 A-d)^{2},
\end{aligned}
$$

respectively. Note that for the outsider to produce a non-negative quantity, we must have that $d<4 A$. Furthermore, also note that the merger is anticompetitive if $d<A$.

An example of an anti-competitive merger reducing the outsider's stock market value is when $\alpha=10, c=6, d=0.95, \beta_{z}=8, \beta_{y}=10, f=$ $2 / 9, \lambda \leq \lambda_{\text {NoMerger }}$ and $\mu$ is sufficiently large. To verify that this example generates the desired result, seven conditions must be checked. First, the merger is anti-competitive after the shock, ie $\pi_{z}^{-}>\pi_{z}$, since $d<A$. Second, it is better to be an insider than an outsider after the shock, ie $\pi_{z}^{+} / 2>\pi_{z}^{-}$, since $16 A d-8 A^{2}+d^{2}>9 \beta_{z} f / 2$. Third, the merger is profitable after the shock, since the first two conditions are satisfied. Fourth, by equation (7), a merger race takes place after the shock, since $\pi_{z}^{+}>2 \pi_{z}$ and $\pi_{z}^{+} / 2>$ $\pi_{z}^{-}$. Fifth, the merger is unprofitable before the shock, ie $\pi_{y}^{+}<2 \pi_{y}$, since 
$(4 A+2 d)^{2} / 9-2 A^{2}<\beta_{y} f$. Sixth, no merger occurs before the shock, since $\lambda \leq \lambda_{\text {NoMerger }}$. Finally, by Proposition 1 , the outsider's stock market value is reduced at the merger announcement, since $\mu$ is sufficiently large and $\pi_{z}^{+} / 2>\pi_{z}^{-}$. QED.

\section{A.6 Proof of Proposition 2}

When the shock is included in the event window, the stock-market reaction is given by $W_{z}^{-}-W_{y}$. By equations (2) and (19),

$$
W_{z}^{-}-W_{y}=\pi_{z}^{-} / r-\left[\frac{r}{\lambda+r} \pi_{y}+\frac{\lambda}{\lambda+r}\left(\frac{r}{r+\mu} \pi_{z}+\frac{\mu}{r+\mu}\left(\pi_{z}^{+}+\pi_{z}^{-}\right) / 3\right)\right] / r .
$$

Simple algebra yields the desired result. QED.

\section{A.7 Proof of Corollary 2 (a)}

The corollary is proved by way of example. Consider once more the linear homogenous good Cournot triopoly in the proof of Corollary 1 (b) and assume the shock to be an increase in demand, ie $\beta_{y}>\beta_{z}$. Assume also that the shock is included in the event window, so that the share-price movements are given by $\Delta W^{\text {merger }}+\Delta W^{\text {shock }}$ as in Proposition 2. Note that the merger is pro-competitive if $d>A$.

An example of a pro-competitive merger increasing the outsider's stock market value is when $\alpha=10, c=6, d=1.25, f=2 / 9, \beta_{y}=10, \beta_{z}=8$ and $\lambda$ is sufficiently small. To verify that this example generates the desired result, five conditions must be checked. First, the merger is pro-competitive after the shock, ie $\pi_{z}^{-}<\pi_{z}$, since $d>A$. Second, the merger is profitable after the shock, ie $\pi_{z}^{+}>2 \pi_{z}$, since $(4 A+2 d)^{2} / 9-2 A^{2}>\beta_{z} f$. Third, it is better to be an insider than an outsider after the shock, since the first two conditions 
are satisfied. Fourth, by equation (7), a merger race takes place after the shock, since $\pi_{z}^{+}>2 \pi_{z}$ and $\pi_{z}^{+} / 2>\pi_{z}^{-}$. Fifth, the merger is unprofitable before the shock, ie $\pi_{y}^{+}<2 \pi_{y}$, since $(4 A+2 d)^{2} / 9-2 A^{2}<\beta_{y} f$. Sixth, no merger occurs before the shock since $\lambda \leq \lambda_{\text {NoMerger }}$. Finally, by Proposition 2 , if the positive trigger effect dominates the negative profit effect, and if $\lambda$ is sufficiently small so that the negative out-of-play effect is negligible, the outsider's share price will increase. The trigger effect dominates the profit effect if $\left(\pi_{z}-\pi_{y}\right)+\left(\pi_{z}^{-}-\pi_{z}\right)>0$. In the numerical example, this condition is fulfilled since $(7 A-d)(A-d) / 9 \beta_{z}+\left(1 / \beta_{z}-1 / \beta_{y}\right) A^{2}>0$. QED. 